\title{
Genetic Polymorphisms in NLRP3
}

\section{Inflammasome-Associated Genes in Patients with B-Cell Non-Hodgkin's Lymphoma}

\author{
Zhi-He Liu' \\ Lin Zhang ${ }^{2}$ \\ Fan-Jing Jing ' \\ Shu-Xin Xiao' \\ Yan Gao' \\ Hai-Yan Bian' \\ Xia Zhao' \\ 'Department of Hematology, The \\ Affiliated Hospital of Qingdao University, \\ Qingdao, 266000, Shandong, People's \\ Republic of China; ${ }^{2}$ Laboratory of \\ Molecular Diagnosis and Regenerative \\ Medicine, The Affiliated Hospital of \\ Qingdao University, Qingdao, 266000, \\ Shandong, People's Republic of China
}

Correspondence: Xia Zhao

Department of Hematology, The Affiliated Hospital of Qingdao University, 16 Jiangsu Road, Shinan District, Qingdao, 266000, Shandong, People's Republic of China

Tel/Fax +86532829 I I 20 I

Email alice-xia@I63.com
Purpose: The role of NLRP3 inflammasome in the progression of many diseases has been increasingly recognized. However, the function of this molecular assembly in the development and progression of B-cell non-Hodgkin's lymphoma remains unclear.

Patients and Methods: In this study, we investigated the polymorphisms in the NLRP3 inflammasome associated genes in 281 patients with B-cell non-Hodgkin's lymphoma and 385 age- and gender-matched healthy controls.

Results: We found that IL-18 (rs1946518) and NFkB-94 ins/del (rs28362491) contributed to susceptibility to B-cell non-Hodgkin's lymphoma. Specifically, the allele "G" in IL-18 (rs1946518) and allele "ins" in NFKB-94 ins/del (rs28362491) were significantly associated with the risk of disease. The AA genotype of CARD8 (rs2043211) and the higher level of serum lactate dehydrogenase (LDH) led to statistically poorer B-cell non-Hodgkin's lymphoma survival. Less frequent genotype TT of CARD8 (rs2043211) was observed in patients with higher LDH level, clinical stages III-IV of disease, and IPI 3-5, although the relationship did not reach statistical significance. However, IPI is an independent prognostic factor for B-cell non-Hodgkin's lymphoma.

Conclusion: IL-18 (rs1946518) and NFkB-94 ins/del (rs28362491) gene polymorphisms appear to be the factors influencing the risk of B-cell non-Hodgkin's lymphoma. CARD8 (rs2043211) polymorphisms are important factors for the survival of patients with this disease.

Keywords: NLRP3, inflammasome, B-cell non-Hodgkin's lymphoma, susceptibility, survival

\section{Introduction}

Non-Hodgkin's lymphoma (NHL) is a group of lymphoproliferative diseases, accounting for a large part of all tumors of immune system. ${ }^{1}$ According to the type of lymphocytes involved, NHLs can be divided into T-cell lymphomas and B-cell lymphomas. The development and pathogenesis of lymphoma is complex, and its specific mechanism is not clear. In normal conditions, B-lymphocytes need specific signals for survival and proliferation. These signals are generated by cells in the lymph nodes. In B-cell non-Hodgkin's lymphoma (B-NHL), the cancer cells are similar to the normal B cells, and they associate the immune inflammatory response with the potential of malignant clone for growth ${ }^{2-4}$.

Genetic analysis of B-NHL tumor microenvironment revealed different genetic characteristics related to the survival. ${ }^{5}$ Functional single nucleotide polymorphisms 
(SNPs) can affect both the inflammatory microenvironment around the malignant tumor ${ }^{6}$ and directly the malignant $\mathrm{B}$ cells. ${ }^{7}$ Inflammasomes contain a number of cytoplasmic NOD-like receptors (NLR). NLRs are involved in the recognition of pathogen-produced molecular patterns by the innate immune. They also recognize molecular patterns associated with intracellular and extracellular damage. ${ }^{8,9}$ More than 20 inflammasomes present in almost every cell have been discovered recently. NLRP3 is one of the most studied members of the NLR receptor family. The NLRP3 inflammasome consists of caspase-1 and the adaptor ASC ("apoptosis-associated speck-like protein”). Important functional parts of ASC are its carboxy-terminal caspase-recruitment domain (CARD) and an amino-terminal pyrin domain (PYD). ${ }^{10}$ The domain CARD8 in ASC binds to the domain CARD8 of caspase-1, forming an assembly which is required for the cleavage and consequent activation of caspase-1. Although the exact role of CARD8 in the inflammasome remains unclear, it is known to function as an inhibitor of NFKB and caspase-1. ${ }^{11-13}$ Caspase-1 can induce the maturation of interleukins IL-1 $\beta$ and IL-18 through cleavage of their inactive precursor proteins (pro-IL-1 $\beta$ and pro-IL-18). Activation of NLRP3 involves two checkpoint activation mechanisms. The first is a typical initiation step which is triggered by a pattern recognition receptor and leads to the expression of pro-IL-1 $\beta$ and NLRP3. The second step involves the assembly and activation of inflammatory molecular complexes induced by different ligands. ${ }^{14,15}$ The inhibition of inflammasomes or neutralization of their products, particularly the interleukins IL-1 $\beta$ and IL-18, has major effects on the development and progression of tumors.

Unsurprisingly, inflammasomes are viewed as promising therapeutic targets for cancer therapy. ${ }^{16}$ There is no data reporting a relation between NHL, especially B-NHL, and polymorphisms in NLRP3 inflammasome so far. Thus, the purpose of this study was to establish if genetic polymorphisms associated with NLRP3 inflammatory signaling (IL-1 $\beta$ rs16944, IL-18 rs1946518, CARD8-C10X rs2043211, and NFkB-94 rs28362491 ins/del) are associated with the B-NHL risk and survival.

\section{Materials and Methods}

\section{Patients and Controls}

A total of 281 consecutive patients with B-NHL diagnosed using the WHO classification criteria were enrolled in the study during the period between May 2010 and December 2018 in the affiliated hospital of Qingdao University. All patients received standard induction chemotherapy based on the latest National Comprehensive Cancer Network (NCCN) guideline at the time of definite diagnosis. The study cohort included 155 males and 126 females. The median age of the patients was 56 years. Samples from 385 age- and gender-matched healthy individuals (233 males and 152 females, median age 48 years) were collected as controls in this study.

The study was approved by the Ethics Committee of the affiliated hospital of Qingdao University, China. All participants provided informed consent, in accordance with the Declaration of Helsinki. Sample collection time was morning for volunteers fasting, while normally patients sample collection time was before treatment.

\section{Sample Preparation and Genotyping}

Formalin-fixed paraffin-embedded (FFPE) bone-marrow aspirates of all patients were used for DNA extraction. In the control group, DNA was extracted from the whole blood. Whole blood samples of the control group were obtained on an empty stomach in the morning.

Genomic DNA (gDNA) was extracted using a TIANamp blood DNA kit according to the manufacturer's instructions. IL-1 $\beta$ (rs16944), IL-18 (rs 1946518) and CARD8-C10X (rs2043211), were purchased from Thermo Fisher Scientific Company. The detection of promoter polymorphism NFkB-94 ins/del ATTG was done using the forward primer: 5'- CCG TGCTGC CTG CGT T $-3^{\prime}$, reverse primer: 5'- GCT GGA GCC GGT AGG GAA- $3^{\prime}$, the probe 1: $5^{\prime}$-VIC- ACC ATT GAT TGG GCC -MGB-3', and the probe 2: 5'-FAM- CGA CCA TTG GGC C -MGB-3'. All PCR reactions were performed in triplicate. Reaction mixtures contained $1 \mu \mathrm{L}$ of DNA, $0.15 \mu \mathrm{L}$ of TaqMan Universal PCR Master Mix, $1.85 \mu \mathrm{L}$ of water and $3 \mu \mathrm{L}$ of Allelic Discrimination Mix. Real-time PCR was performed using ABI 7500 real-time PCR System (SDS, PE Biosystems) in the following conditions: $50^{\circ} \mathrm{C}$ for $2 \mathrm{~min}, 95^{\circ} \mathrm{C}$ for $10 \mathrm{~min}$, and then 40 cycles of amplification $\left(92^{\circ} \mathrm{C}\right.$ denaturation for $15 \mathrm{~s}, 62^{\circ} \mathrm{C}$ annealing/ extension for $60 \mathrm{~s}$ ). ABI 7500 Sequence Detection System (SDS) 1.3.1 was used to analyze the genotypes.

\section{Multivariable Logistic Regression}

Multivariable logistic regression analysis was applied to predict the association between genetic polymorphisms of NLRP3 inflammasome-associated genes and B-NHL susceptibility. 


\section{Cox Regression Analysis}

COX regression analysis was used to conduct multivariate analysis of survival in patients with B-NHL, and various factors included pathologic types, IPI, LDH and NLRP3 genetic polymorphisms, such as IL-18 (rs1946518), IL-1 $\beta$ (rs16944), CARD8 (rs2043211) and NFkB-94 (ins/del ATTG).

\section{Survival Analysis}

Overall survival (OS) was defined as the time from the date of diagnosis to the date of death of any cause or the last follow-up.

\section{Statistical Analysis}

The continuous variables are presented as mean $\pm \mathrm{SD}$, and the categorical variables - as frequencies and percentages (\%). The genotype frequencies of the Hardy-Weinberg equilibrium were tested by standard chi-square test. The association between genotype and disease risk was analyzed by calculating the odds ratio (OR) and the corresponding 95\% confidence interval (CI). The OS was analyzed by the Kaplan-Meier method (Log rank test). Cox regression analysis was performed to assess the risk factors associated with the OS in patients with B-NHL. GraphPad prism 6.0 system was used for statistical analysis. In this work, bilateral $P<0.05$ was considered statistically significant.

\section{Results}

\section{The Base Information of Patients with B-NHL in This Study}

The research included 281 B-NHL patients (155 males and 126 females). The age of $62.2 \%$ patients $175 / 281$ ) was below or equal to 60 while $81.1 \%$ patients $(228 / 281)$ were mid-stage cancer and last-stage cancer. For most of the patients, LDH level were normal (157/281). Pathological changes are below or equal 2(196/281), IPI is below or equal (181/281). There is no B symptom (206/ $281)$ and no bone marrow involvement (244/281). DLBCL was the common pathological subtype, followed by FL, MCL and MZL (Table 1).

Table I The Base Information of Patients with B-NHL in This Study

\begin{tabular}{|c|c|c|c|}
\hline \multicolumn{2}{|l|}{ Characteristics } & \multirow{2}{*}{$\begin{array}{c}\text { Case (n) } \\
175\end{array}$} & \multirow{2}{*}{$\begin{array}{c}\text { Percentage (\%) } \\
62.28\end{array}$} \\
\hline Age/year & $\leq 60 y$ & & \\
\hline & $>60 y$ & 106 & 37.72 \\
\hline \multirow[t]{2}{*}{ Sex } & Male & 155 & 55.16 \\
\hline & Female & 126 & 44.84 \\
\hline \multirow[t]{2}{*}{ Stage } & I-II & 53 & 18.86 \\
\hline & III-IV & 228 & 81.14 \\
\hline \multirow[t]{2}{*}{ LDH (U/L) } & $<230$ & 157 & 55.87 \\
\hline & $\geq 230$ & 124 & 44.13 \\
\hline \multirow[t]{2}{*}{ Extranodal involvement } & $0 \sim 2$ & 196 & 69.75 \\
\hline & $\geq 2$ & 85 & 30.25 \\
\hline \multirow[t]{2}{*}{ Bone marrow involvement } & $(-)$ & 244 & 86.83 \\
\hline & $(+)$ & 37 & 13.17 \\
\hline \multirow[t]{2}{*}{ B symptoms } & $(-)$ & 206 & 73.31 \\
\hline & $(+)$ & 75 & 26.69 \\
\hline \multirow[t]{2}{*}{ IPI } & $0 \sim 2$ & 185 & 65.84 \\
\hline & $3 \sim 5$ & 96 & 34.16 \\
\hline \multirow[t]{5}{*}{ Pathologic type } & DLBCL & 188 & 66.90 \\
\hline & $\mathrm{FL}$ & 48 & 17.08 \\
\hline & $\mathrm{MCL}$ & 15 & 5.34 \\
\hline & MZL & 17 & 6.05 \\
\hline & Others & 13 & 4.63 \\
\hline
\end{tabular}




\section{The Relationship Between Genetic} Polymorphism in NLRP3 Inflammasome Associated Genes and B-NHL

\section{Susceptibility}

Both IL-18 GG (rs1946518) $\left(\chi^{2}=122.789, P<0.0001\right)$ and NFкB-94 ins/del (rs28362491) $\left(\chi^{2}=11.7041, P=0.0029\right)$ were found to be significantly associated with B-NHL. No significant differences were found in the distribution of IL-1 $\beta$ (rs16944) $\left(\chi^{2}=1.1692, P=0.5574\right)$ and CARD8 (rs2043211) $\quad\left(\chi^{2}=1.5652, \quad P=0.4572\right) \quad$ polymorphisms between the B-NHL and the controls (Table 2).

In this study, DLBCL was found to be the most common pathological subtype, therefore, we discuss relationships in gene polymorphism and DLBCL and FL susceptibility. We found IL18 GG (rs1946518) $\left(\chi^{2}=106.3, P<0.0001\right)$ and NFkB-94 ins/ins (rs28362491) $\left(\chi^{2}=12.67, P=0.0018\right)$ in DLBCL, compared to control group, which was statistically significant. But in the patients with FL, only IL-18 GG (rs1946518) $\left(\chi^{2}=30.51\right.$, $P<0.0001$ ) were higher than the control group (Table 3).

\section{The Distribution of NLRP3 Alleles and Their Association with B-NHL \\ Susceptibility}

To investigate the relationship between the alleles of IL-18 (rs1946518) and NFkB-94 ins/del (rs28362491) and B-NHL susceptibility, multivariate logistic regression analysis was performed controlling for age and gender. Analysis of the alleles of IL-18 (rs1946518) demonstrated a significantly increased risk among patients carrying the allele " $\mathrm{G}$ " in all study subjects in dominant model (OR $=4.271$, 95\% $\mathrm{CI}=3.273-5.575, P<0.0001)$. In addition, the "ins" allele of NFkB-94 ins/del (rs28362491) was linked to the increased risk of B-NHL $(\mathrm{OR}=1.265,95 \% \mathrm{CI}=1.010-1.586, P=0.0194)$ (Table 4).

\section{The Association of NLRP3 Inflammasome Genetic Polymorphisms and B-NHL Patient Characteristics}

Next, we investigated the association between NLRP3 inflammasome genetic polymorphisms and clinical characteristics of patients including age, gender, level of serum lactate dehydrogenase (LDH), clinical stage of disease, international prognostic index (IPI), and sites of extranodal involvement. The results demonstrated that NLRP3 inflammasome genetic polymorphisms were not associated with age, sex, LDH level, clinical stages, extranodal involvement, IPI and bone marrow involvement (Table 5).

\section{Higher LDH Level and CARD8 (rs20432 II) AA Genotype Contributed to Poorer B-NHL Survival}

For each SNP, the patients were stratified according to their specific genotypes. The survival data are shown in Figure 1.

Table 2 The Distribution of NLRP3 Genetic Polymorphisms and Their Association with B-NHL Susceptibility

\begin{tabular}{|c|c|c|c|c|}
\hline Polymorphisms & Case (n) & Control (n) & $\chi^{2}$ & $P$ \\
\hline \multicolumn{5}{|l|}{ IL-I8 (rs|9465I8) } \\
\hline GG & 187 (69.78\%) & 104 (27.01\%) & 122.789 & $<0.0001$ \\
\hline GT & 71 (26.49\%) & $203(52.73 \%)$ & & \\
\hline $\mathrm{TT}$ & 10 (3.73\%) & 78 (20.26\%) & & \\
\hline \multicolumn{5}{|l|}{ IL-I $\beta$ (rs|6944) } \\
\hline GG & $83(29.75 \%)$ & $100(25.97 \%)$ & & \\
\hline GA & $|3|$ (46.95\%) & 189 (49.09\%) & 1.1692 & 0.5574 \\
\hline AA & 65 (23.30\%) & 96 (24.94\%) & & \\
\hline \multicolumn{5}{|l|}{ CARD8 (rs20432II) } \\
\hline AA & $65(26.21 \%)$ & II 8 (30.65\%) & 1.5652 & 0.4572 \\
\hline AT & II 5 (46.37\%) & 172 (44.68\%) & & \\
\hline TT & $68(27.42 \%)$ & 95 (24.67\%) & & \\
\hline NFKB-94 (ins/del ATTG) & & & | I.704| & 0.0029 \\
\hline ins/ins & I I 6 (43.28\%) & 119 (30.91\%) & & \\
\hline ins/del & $100(37.31 \%)$ & $189(49.09 \%)$ & & \\
\hline $\mathrm{del} / \mathrm{del}$ & 52 (19.40\%) & 77 (20.00\%) & & \\
\hline
\end{tabular}

Note: Statistical significant $P$ values and corresponding lines are displayed in bold. 
Table 3 The Distribution of NLRP3 Genetic Polymorphisms and Their Association with DLBCL and FL Susceptibility

\begin{tabular}{|c|c|c|c|c|c|c|c|}
\hline \multirow[t]{2}{*}{ Polymorphisms } & \multirow[t]{2}{*}{ Control (n) } & \multicolumn{3}{|c|}{ DLBCL } & \multicolumn{3}{|c|}{$\mathbf{F L}$} \\
\hline & & Case (n) & $\chi^{2}$ & $P$ & Case (n) & $\chi^{2}$ & $P$ \\
\hline \multicolumn{8}{|l|}{ IL-I8(rs|9465|8) } \\
\hline GG & 104(27.01\%) & |32(7|.74\%) & 106.3 & $<0.0001$ & $31(65.96 \%)$ & 30.51 & $<0.000$ I \\
\hline GT & $203(52.73 \%)$ & $46(25.00 \%)$ & & & 14(29.79\%) & & \\
\hline TT & $78(20.26 \%)$ & $6(3.26 \%)$ & & & $2(4.25 \%)$ & & \\
\hline \multicolumn{8}{|l|}{ IL-I $\beta($ rs I 6944) } \\
\hline GG & 100 (25.97\%) & 54 (29.19\%) & 1.053 & 0.5906 & $17(35.42 \%)$ & 4.311 & 0.1159 \\
\hline GA & $189(49.09 \%)$ & 91 (49.19\%) & & & $16(33.33 \%)$ & & \\
\hline AA & $96(24.94 \%)$ & 40 (21.62\%) & & & $15(31.25 \%)$ & & \\
\hline \multirow{2}{*}{\multicolumn{8}{|c|}{$\begin{array}{l}\text { CARD8 } \\
(\mathrm{rs} 20432 \mathrm{II})\end{array}$}} \\
\hline & & & & & & & \\
\hline AA & II8(30.65\%) & $44(27.33 \%)$ & 0.784 & 0.6757 & $12(26.09 \%)$ & 2.2 & 0.3329 \\
\hline AT & I72(44.68\%) & $78(48.45 \%)$ & & & $18(39.13 \%)$ & & \\
\hline TT & $95(24.67 \%)$ & $39(24.22 \%)$ & & & $16(34.78 \%)$ & & \\
\hline \multirow{2}{*}{\multicolumn{8}{|c|}{$\begin{array}{l}\text { NFKB-94(ins/del } \\
\text { ATTG) }\end{array}$}} \\
\hline & & & & & & & \\
\hline ins/ins & $119(30.91 \%)$ & $83(45.86 \%)$ & 12.67 & 0.0018 & $17(36.17 \%)$ & 0.772 & 0.6797 \\
\hline ins/del & 189(49.09\%) & $65(35.91 \%)$ & & & $20(42.55 \%)$ & & \\
\hline del/del & $77(20.00 \%)$ & $33(18.23 \%)$ & & & $10(21.28 \%)$ & & \\
\hline
\end{tabular}

Note: Statistically significant $P$ values and corresponding lines are displayed in bold.

Table 4 The Distribution of NLRP3 Alleles and Their Association with B-NHL Susceptibility

\begin{tabular}{|c|c|c|c|c|c|}
\hline Alleles & Case (n) & Control (n) & $\chi^{2}$ & $\mathbf{P}$ & OR (95\% Cl) \\
\hline \multicolumn{6}{|l|}{ IL-I8 (rs | 9465I8) } \\
\hline G & 445 (83.02\%) & $4 I I(53.38 \%)$ & 123.00 & $<0.0001$ & 4.27 I (3.273-5.574) \\
\hline $\mathrm{T}$ & 91 (16.98\%) & 359 (46.62\%) & & & \\
\hline \multicolumn{6}{|l|}{ IL-I $\beta$ (rs I 6944) } \\
\hline G & 297 (53.23\%) & $389(50.52 \%)$ & 0.9489 & 0.33 & $1.115(0.8960-1.386)$ \\
\hline A & 261 (46.77\%) & 381 (49.48\%) & & & \\
\hline \multicolumn{6}{|l|}{ CARD8 (rs20432II) } \\
\hline$A$ & $245(49.40 \%)$ & 408 (52.99\%) & $1.558 \mid$ & 0.2119 & $0.8660(0.6909-1.086)$ \\
\hline $\mathrm{T}$ & $251(50.60 \%)$ & $362(47.01 \%)$ & & & \\
\hline \multicolumn{6}{|l|}{ NFKB-94(ins/del ATTG) } \\
\hline ins & $332(61.94 \%)$ & $427(55.45 \%)$ & 5.4612 & 0.0194 & $1.265(1.010-1.586)$ \\
\hline del & $204(38.06 \%)$ & 343 (44.55\%) & & & \\
\hline
\end{tabular}

Note: Statistically significant $P$ values and corresponding lines are displayed in bold.

The AA genotype of CARD8 (rs2043211) led to statistically poorer B-NHL-specific survival $(P=0.0381)$. There was no significant difference in the OS of patients with IL-18 (rs1946518) $(P=0.8156)$, CARD8 (rs2043211) $(P=0.1685)$, NFкB -94 ins/del ATTG $(P=0.7638)$, or IL-1 $\beta$ (rs16944) $(P=0.9311)$. However, in terms with the SNP of CARD8 (rs2043211), the AA genotype of CARD8 (rs2043211) was associated with statistically poorer B-NHL survival compared to the TT genotype of CARD8 (rs2043211) $(P=0.047)$. The higher LDH level was linked to statistically poorer B-NHL survival in comparison to the patients with normal LDH level $(P=0.04691)$ (Figure 1). 


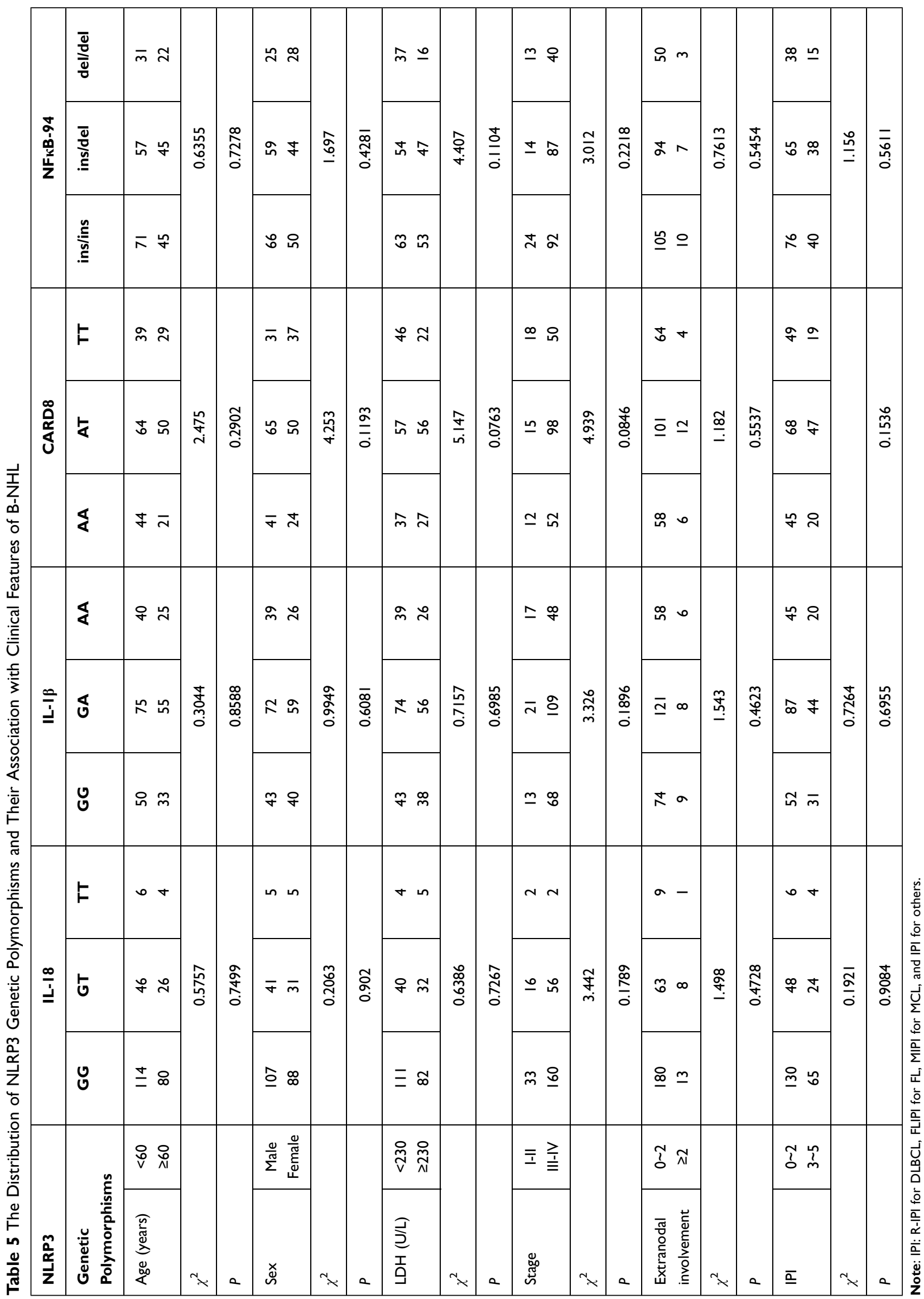



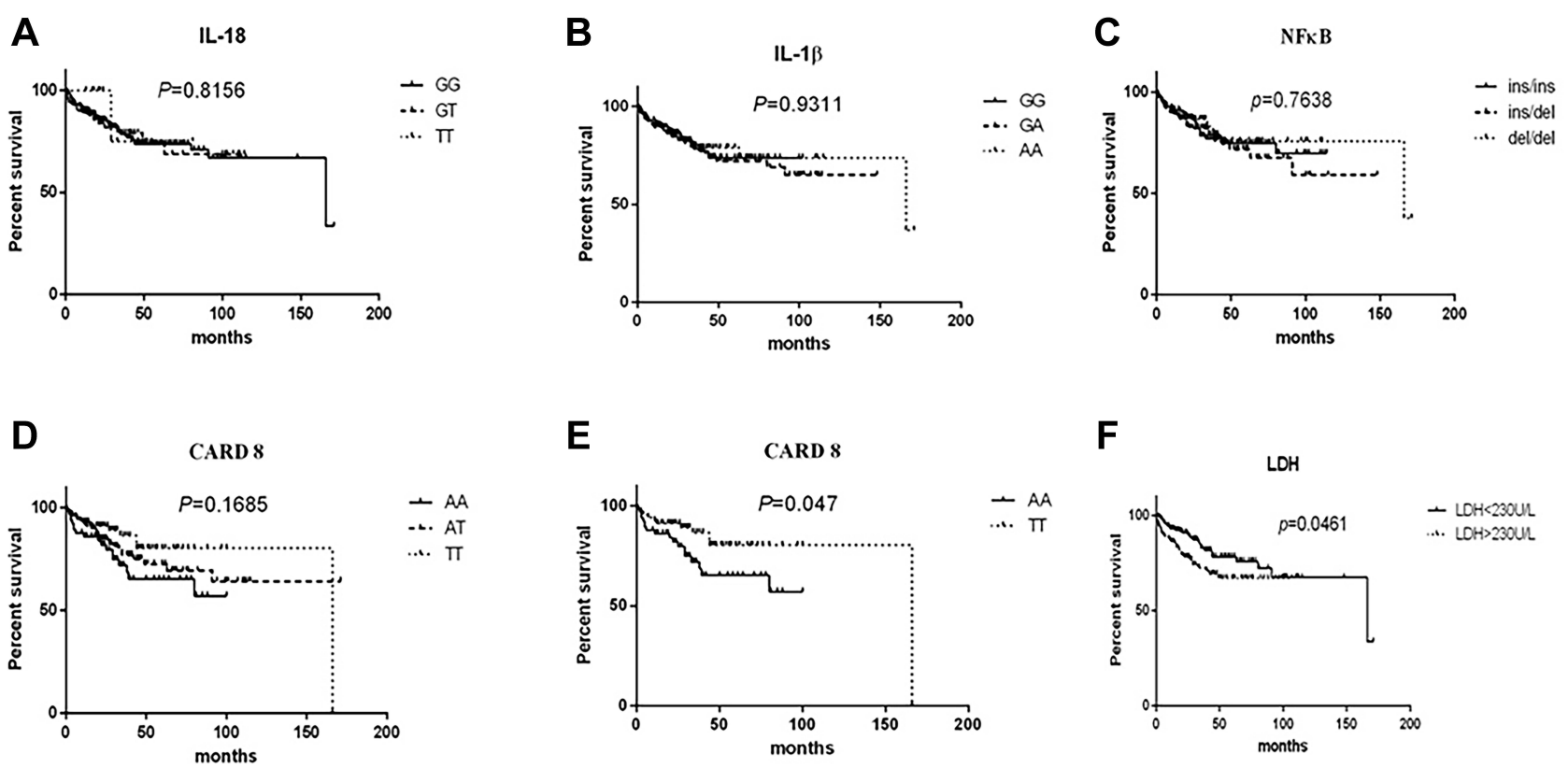

Figure I Kaplan-Meier curves of IL-I8 (rs 19465 I8), IL-I 3 (rs 16944), CARD8 (rs20432I I) NFKB-94 ins/del ATTG genotypes and LDH in patients with B-NHL. Log-rank P values compared with the different genotypes are shown, and CARD8 (rs20432II) AA genotype and higher LDH contributed to poorer B-NHL survival.

\section{Multivariate Analysis of Survival of Patients with B-NHL in This Study}

In order to find the clinically relevant factors in B-NHL patients, we used cox regression analysis for multiple factors, including pathological subtype, LDH, IPI, NFkB94 (ins/del ATTG), IL-18 (rs1946518), IL-1ß (rs16944), CARD8 (rs2043211). Our analyses revealed that IPI is the factor for B-BHL $(\mathrm{p}=0.030)$ (Table 6).

\section{Discussion}

Understanding the mechanisms by which the immune system affects tumor development and progression is still one of the most challenging issues in oncology. Epidemiological, genetic and molecular studies have shown that there is a close relationship between inflammation and cancers. ${ }^{17}$ In this study, we investigated genetic polymorphisms related to NLRP3 inflammasome associated genes in B-NHL patients. We studied the polymorphisms of NLRP3 pathway genes IL-1 $\beta$ (rs16944), IL-18 (rs1946518), CARD8 (rs2043211) and NFkB-94 ins/del ATTG (rs28362491) in 281 patients with B-NHL and 385 healthy controls.

It remains uncertain which cellular signaling events mediate the assembly and activation of inflammasomes. The apoptotic speck-like protein containing the caspase recruitment domain (ASC) is an important component of the fully assembled and active NLRP3 inflammasomes. ${ }^{18}$ Inflammasomes may act at the cellular autonomic level to remove cancerous precursors through apoptosis. Conversely, inflammasomes may stimulate the production of nutritional factors in cancer cells and their stroma. Caspase-1 activation in inflammatory cells promotes the circulation that leads to aseptic inflammation and carcinogenesis. On the other hand, inflammasomes stimulate anticancer immune responses in antigen-presenting cells. The assembly of the inflammasome complex results in the caspase-1 activation, which triggers the maturation and secretion of proinflammatory cytokines, including IL-1 $\beta$ and IL-18. The inflammasomes inhibition or neutralization of their products, particularly IL-1 $\beta$ and IL-18, has major impacts on carcinogenesis and progression of tumor. This makes inflammasomes a promising anticancer therapeutic target. ${ }^{16}$

IL-18 is a pleiotropic, proinflammatory cytokine, which has dual effect on tumorigenesis and cancer progression. Cytokine IL-18 belongs to the IL-1 superfamily produced by multiple immune and non-immune cells. ${ }^{19,20}$ IL-18 plays a role in the host's response to tumorigenesis and angiogenesis. Both IL-18-607 (C/A) and IL-18-137 (G/C) polymorphisms were linked to a significant increase in the risk of cancer. Since IL-18 plays important roles in the elimination of cancer cells by immune response to 
Table 6 Cox Regression Analysis for Survival of Patients with B-NHL

\begin{tabular}{|c|c|c|c|c|}
\hline \multirow[t]{2}{*}{ Factors } & \multirow[t]{2}{*}{$P$} & \multirow[t]{2}{*}{ HR } & \multicolumn{2}{|c|}{$95.0 \% \mathrm{Cl}$ for $\mathrm{HR}$} \\
\hline & & & Lower & Upper \\
\hline \multicolumn{5}{|l|}{ Pathologic } \\
\hline Aggressive & 0.920 & 1.032 & 0.562 & 1.893 \\
\hline \multicolumn{5}{|l|}{ LDH(U/L) } \\
\hline$\geq 230$ & 0.780 & 1.098 & 0.570 & 2.114 \\
\hline \multicolumn{5}{|l|}{ IPI } \\
\hline $3 \sim 5$ & 0.030 & 2.101 & 1.075 & 4.098 \\
\hline \multicolumn{5}{|c|}{ NFKB-94(ins/del ATTG) } \\
\hline $\mathrm{del} / \mathrm{del}$ & 0.260 & 1.000 & & \\
\hline ins/ins & 0.388 & 1.495 & 0.599 & 3.729 \\
\hline ins/del & 0.121 & 2.040 & 0.829 & 5.019 \\
\hline \multicolumn{5}{|c|}{ IL-I8(rs|9465|8) } \\
\hline $\mathrm{TT}$ & 0.846 & 1.000 & & \\
\hline GG & 0.633 & 1.626 & 0.222 & 11.936 \\
\hline GT & 0.733 & 1.433 & 0.181 & $\mid 1.321$ \\
\hline \multicolumn{5}{|l|}{ IL-I $\beta($ rs I 6944) } \\
\hline GG & 0.944 & 1.000 & & \\
\hline AA & 0.756 & 0.878 & 0.386 & 1.997 \\
\hline GA & 0.778 & 0.907 & $0.46 I$ & 1.785 \\
\hline \multicolumn{5}{|c|}{ CARD8(rs20432II) } \\
\hline TT & 0.401 & 1.000 & & \\
\hline AA & 0.226 & 1.618 & 0.742 & 3.525 \\
\hline AT & 0.750 & 1.128 & 0.538 & 2.366 \\
\hline
\end{tabular}

Note: Statistically significant $P$ values and corresponding lines are displayed in bold.

cancer, cancer angiogenesis, metastasis, proliferation and immune escape, the polymorphisms in the IL-18 gene may seriously influence the risk of cancer. ${ }^{21-24}$

In this study, we found that the IL-18 (rs1946518) polymorphism was significantly associated with the susceptibility to B-NHL, while the GG genotype in IL-18 was significantly associated with the risk of B-NHL. We also observed a significantly increased risk of B-NHL among the carriers of the allele "G" of IL-18 (rs1946518). Further analysis of common subtypes of lymphoma found that the GG genotype in IL-18 was significantly associated with the risk of DLBCL and FL. However, no association was found between the IL-18 (rs1946518) polymorphism and the clinical characteristics of B-NHL patients. We also found no significant difference in the overall survival of B-NHL patients with IL-18 (rs1946518).

The IL-1 $\beta$ gene is located on the chromosome $2 \mathrm{q} 14$, and its expression is related to a variety of cancer types. ${ }^{25}$ The IL-1 $\beta$ gene polymorphisms can be associated with various malignancies including gastric cancer, lung cancer and hepatocellular carcinoma, with high expression of IL$1 \beta$ related to poor survival in cancers. ${ }^{26-28}$

In our study, we found no significant difference in the distribution of IL-1 $\beta$ (rs16944) polymorphisms between the B-NHL patients and controls. There was no association between IL-1 $\beta$ (rs16944) polymorphisms and clinical manifestations of B-NHL patients. We did not find a significant difference in the overall survival of patients with IL-1 $\beta$ (rs16944).

Caspase-associated recruitment domains (CARD) is a protein-protein interaction module commonly observed in proteins involved in apoptosis, NFאB activation, and cytokine regulation. Overexpression of CARD8 could induce apoptosis of transfected cells. CARD8 is a signaling molecule involved in both the regulation of caspase-1 and NFKB activation. ${ }^{12,13}$

We found that CARD8 (rs2043211) polymorphisms were significant for the B-NHL patients' survival. From our results, the AA genotype of CARD8 (rs2043211) led to statistically poorer B-NHL survival compared to the TT 
genotype of CARD8 (rs2043211). There was no association between CARD8 (rs2043211) polymorphisms and clinical manifestations of B-NHL patients.

The importance of cancer-related inflammation was emphasized in the recent studies. These studies demonstrated that growth and progression of tumour depend on activation of NFKB, which plays the role of a key controller of the innate immune response. ${ }^{29,30}$ There are several studies of this polymorphism in cancer and other diseases. $^{31-33}$ These studies found that NFאB-94 ins/del polymorphism may influence the risk of cancer in Asian population. The variant allele of NFkB-94 ins/del ATTG (rs28362491) polymorphism was shown to be associated with higher risk of sporadic CRC in Malaysian population, and functional NFkB-94 ins/del ATTG polymorphism is associated with CSCC.

In our research, we found that NFאB-94 ins/del (rs28362491) was significantly associated with B-NHL, and the "ins" allele carriers of NFкB-94 ins/del (rs28362491) have increased risk for B-NHL. Further analysis of common subtypes of lymphoma found that NFאB polymorphism was significantly associated with the susceptibility to DLBCL, while the "ins/ins' genotype in NFkB was significantly associated with the risk of DLBCL. However, no association was found between the NFKB-94 ins/del (rs28362491) polymorphism and the clinical characteristics of B-NHL patients. We also found no significant difference in the overall survival of B-NHL patients with NFkB-94 ins/del (rs28362491).

The previous study reported that high levels of serum lactate dehydrogenase at the time of initial diagnosis and early stages of progression may be associated with reduced survival in patients with follicular lymphoma. ${ }^{34}$ Our research is consistent with this conclusion and showed that the higher LDH level led to statistically poorer B-NHL survival.

We used cox regression analysis including pathological subtype, LDH, IPI, NFкB-94 (ins/del ATTG), IL-18 (rs1946518), IL-1 $\beta$ (rs16944), CARD8 (rs2043211). We found IPI is the independent prognostic factor while LDH and CARDS (rs2043211) polymorphisms is prognostic factor but not the independent prognostic factor. In order to find the factors in B-NHL patients, we used cox regression analysis for multiple factors, such as, pathological subtype, LDH, IPI, NFкB-94 ins/del ATTG), IL-18 (rs1946518), IL-1 $\beta$ (rs16944), CARD8 (rs2043211, all of which resulted in the conclusion that IPI is the factor for B-BHL.

\section{Conclusion}

Our results suggest that IL-18 (rs1946518) and NFkB-94 ins/del (rs28362491) gene polymorphisms are the factors that can influence the susceptibility to B-NHL. The interactions of these genes with B-NHL-related clinical characteristics may have a synergetic effect that can further enhance B-NHL development. CARD8 (rs2043211) polymorphisms were particularly significant for B-NHL survival. These polymorphisms may be used as prognostic indicators in patients with B-NHL.

\section{Author Contributions}

XZ designed and conceptualized study; XZ, ZL, LZ, FJ and $\mathrm{SX}$ took part in study design, collection of data and interpretation; ZL, LZ, YG, HB and XZ analyzed data and prepared article; XZ provided support.

All authors made a significant contribution to the work reported, whether that is in the conception, study design, execution, acquisition of data, analysis and interpretation, or in all these areas; took part in drafting, revising or critically reviewing the article; gave final approval of the version to be published; have agreed on the journal to which the article has been submitted; and agree to be accountable for all aspects of the work.

\section{Funding}

This work was supported by the China Postdoctoral Science Foundation (Grant Number 2020M682128).

\section{Disclosure}

The authors declare that there are no conflicts of interest regarding the publication of this work.

\section{References}

1. Chaudhari K, Rizvi S, Syed BA. Non-Hodgkin lymphoma therapy landscape. Nat Rev Drug Discov. 2019;18(9):663-664. doi:10.1038/ d41573-019-00051-6

2. Mottok A, Hung SS, Chavez EA, et al. Integrative genomic analysis identifies key pathogenic mechanisms in primary mediastinal large B-cell lymphoma. Blood. 2019;134(10):802-813. doi:10.1182/ blood.2019001126

3. Larabi A, Barnich N, Nguyen HTT. New insights into the interplay between autophagy, gut microbiota and inflammatory responses in IBD. Autophagy. 2020;16:38-51.

4. Nesic M, EI-Galaly TC, Bøgsted M, et al. Mutational landscape of immune surveillance genes in diffuse large B-cell lymphoma. Expert Rev Hematol. 2020;13:655-668.

5. Furuse M, Kuwabara H, Ikeda N, et al. PD-L1 and PD-L2 expression in the tumor microenvironment including peritumoral tissue in primary central nervous system lymphoma. BMC Cancer. 2020;20(1):277. doi:10.1186/s12885-020-06755-y 
6. Wang PY, Li JH, Liu YM, et al. Single nucleotide polymorphisms in ZNRD1-AS1 increase cancer risk in an Asian population. Oncotarget. 2017;8(6):10064-10070. doi:10.18632/oncotarget.14334

7. Jiao J, Lv Z, Zhang P, et al. AID assists DNMT1 to attenuate BCL6 expression through DNA methylation in diffuse large B-cell lymphoma cell lines. Neoplasia. 2020;22(3):142-153. doi:10.1016/j.neo.2020.01.002

8. Jiang $\mathrm{XN}$, Yu BH, Yan WH, et al. Epstein-Barr virus-positive diffuse large B-cell lymphoma features disrupted antigen capture/presentation and hijacked T-cell suppression. Oncoimmunology. 2019;9 (1):1683346. doi:10.1080/2162402X.2019.1683346

9. Rathinam VA, Fitzgerald KA. Inflammasome complexes: emerging mechanisms and effector functions. Cell. 2016;165(4):792-800. doi:10.1016/j.cell.2016.03.046

10. Lavallard V, Cottet-Dumoulin D, Wassmer CH, et al. NLRP3 inflammasome is activated in rat pancreatic islets by transplantation and hypoxia. Sci Rep. 2020;10(1):7011. doi:10.1038/s41598-020-64054-9

11. Shinar Y, Ceccherini I, Rowczenio D, et al. ISSAID/EMQN best practice guidelines for the genetic diagnosis of monogenic autoinflammatory diseases in the next-generation sequencing era. Clin Chem. 2020;66(4):525-536. doi:10.1093/clinchem/hvaa024

12. Chen H, Deng Y, Gan X, et al. NLRP12 collaborates with NLRP3 and NLRC4 to promote pyroptosis inducing ganglion cell death of acute glaucoma. Mol Neurodegener. 2020;15(1):26. doi:10.1186/ s13024-020-00372-w

13. Mitchell PS, Sandstrom A, Vance RE. The NLRP1 inflammasome: new mechanistic insights and unresolved mysteries. Curr Opin Immunol. 2019;60:37-45. doi:10.1016/j.coi.2019.04.015

14. Watany MM, Elmazny MI, Nasif EM. Interleukin-31 interaction with inflammasome: a promising diagnostic and prognostic panel for early sepsis identification in critically ill patients. Cytokine. 2020;131:155102. doi:10.1016/j.cyto.2020.155102

15. Yu JW, Lee MS. Mitochondria and the NLRP3 inflammasome: physiological and pathological relevance. Arch Pharm Res. 2016;39 (11):1503-1518. doi:10.1007/s12272-016-0827-4

16. Xie C, Ge M, Jin J, et al. Mechanism investigation on bisphenol S-induced oxidative stress and inflammation in murine RAW264.7 cells: the role of NLRP3 inflammasome, TLR4, Nrf2 and MAPK. $J$ Hazard Mater. 2020;394:122549. doi:10.1016/j.jhazmat.2020.122549

17. Murata M. Inflammation and cancer. Environ Health Prev Med. 2018;23(1):50. doi:10.1186/s12199-018-0740-1

18. Xiao FJ, Zhang D, Wu Y, et al. miRNA-17-92 protects endothelial cells from erastin-induced ferroptosis through targeting the A20ACSL4 axis. Biochem Biophys Res Commun. 2019;515(3):448-454. doi:10.1016/j.bbrc.2019.05.147

19. Hu Z, Wu D, Zhao Y, et al. Inflammatory cytokine profiles in the crevicular fluid around clinically healthy dental implants compared to the healthy contralateral side during the early stages of implant function. Arch Oral Biol. 2019;108:104509. doi:10.1016/j.archoralbio.2019.104509

20. Sedimbi SK, Hägglöf T, Garimella MG, et al. Combined proinflammatory cytokine and cognate activation of invariant natural killer $\mathrm{T}$ cells enhances anti-DNA antibody responses. Proc Natl Acad Sci USA. 2020;117(16):9054-9063. doi:10.1073/pnas.1920463117

21. Zhang A, Yu J, Yan S, et al. The genetic polymorphism and expression profiles of NLRP3 inflammasome in patients with chronic myeloid leukemia. Hum Immunol. 2018;79(1):57-62. doi:10.1016/j. humimm.2017.10.013
22. Zhao X, Hua M, Yan S, et al. The genetic polymorphisms of NLRP3 inflammasome associated with $\mathrm{T}$ helper cells in patients with multiple myeloma. J Immunol Res. 2018;2018:7569809. doi:10.1155/2018/ 7569809

23. Wang H, Hua M, Wang S, et al. Genetic polymorphisms of IL-18 rs1946518 and IL-1 $\beta$ rs16944 are associated with prognosis and survival of acute myeloid leukemia. Inflamm Res. 2017;66(3):249258. doi:10.1007/s00011-016-1012-4

24. Arima K, Komohara Y, Bu L, et al. Downregulation of 15-hydroxyprostaglandin dehydrogenase by interleukin- $1 \beta$ from activated macrophages leads to poor prognosis in pancreatic cancer. Cancer Sci. 2018;109(2):462-470. doi:10.1111/cas. 13467

25. Shahzad MN, Ijaz I, Naqvi SSZH, et al. Association between interleukin gene polymorphisms and multiple myeloma susceptibility. Mol Clin Oncol. 2020;12(3):212-224.

26. Mendoza-Rodríguez MG, Ayala-Sumuano JT, García-Morales L, et al. IL-1 $\beta$ inflammatory cytokine-induced TP63 isoform $\triangle$ NP63 $\alpha$ signaling cascade contributes to cisplatin resistance in human breast cancer cells. Int J Mol Sci. 2019;20(2):E270. doi:10.3390/ ijms 20020270

27. Moonen RM, Huizing MJ, Gonzalez-Luis GE, et al. Risk of necrotizing enterocolitis associated with the single nucleotide polymorphisms VEGF C-2578A, IL-18 C-607A, and IL-4 receptor $\alpha$-chain A-1902G: a valiation study in a prospective multicenter cohort. Front Pediatr. 2020;8:45. doi:10.3389/fped.2020.00045

28. Yazdi AS, Ghoreschi K. The interleukin-1 family. Adv Exp Biol. 2016;941:21-29.

29. Roy K, Mitchell S, Liu Y, et al. A regulatory circuit controlling the dynamics of nfkb crel transitions $\mathrm{b}$ cells from proliferation to plasma cell differentiation. Immunity. 2019;50(3):616-628. doi:10.1016/j. immuni.2019.02.004

30. Chakraborty C, Sharma AR, Sharma G, et al. The interplay among miRNAs, major cytokines, and cancer-related inflammation. Mol Ther Nucleic Acids. 2020;20:606-620. doi:10.1016/j. omtn.2020.04.002

31. Liu W, Guo W, Hang N, et al. MALT1 inhibitors prevent the development of DSS-induced experimental colitis in mice via inhibiting NF- $\mathrm{KB}$ and NLRP3 inflammasome activation. Oncotarget. 2016;7 (21):30536-30549. doi:10.18632/oncotarget.8867

32. Lazarian G, Friedrich C, Quinquenel A, et al. Stabilization of $\beta$ catenin upon B-cell receptor signaling promotes NF- $\mathrm{kB}$ target genes transcription in mantle cell lymphoma. Oncogene. 2020;39 (14):2934-2947. doi:10.1038/s41388-020-1183-x

33. Chen F, Liu F, Yan L, et al. A functional haplotype of NFKB1 influence susceptibility to oral cancer: a population-based and in vitro study. Cancer Med. 2018;7(5):2211-2218. doi:10.1002/ cam 4.1453

34. Murakami S, Kato H, Higuchi Y, et al. Prediction of high risk for death in patients with follicular lymphoma receiving rituximab plus cyclophosphamide, doxorubicin, vincristine, and prednisolone in first-line chemotherapy. Ann Hematol. 2016;95(8):1259-1269. doi:10.1007/s00277-016-2690-2 


\section{Publish your work in this journal}

The Journal of Inflammation Research is an international, peerreviewed open-access journal that welcomes laboratory and clinical findings on the molecular basis, cell biology and pharmacology of inflammation including original research, reviews, symposium reports, hypothesis formation and commentaries on: acute/chronic inflammation; mediators of inflammation; cellular processes; molecular mechanisms; pharmacology and novel anti-inflammatory drugs; clinical conditions involving inflammation. The manuscript management system is completely online and includes a very quick and fair peerreview system. Visit http://www.dovepress.com/testimonials.php to read real quotes from published authors.

Submit your manuscript here: https://www.dovepress.com/journal-of-inflammation-research-journal 